\title{
A new diploid chromosome number in Gymnopleurus Illiger, 1803 (Coleoptera: Scarabaeidae, Scarabaeinae) from Haryana, India
}

\author{
Paramjeet Kaur ${ }^{1}$, Abhay Singh Yadav ${ }^{2}$ \\ 1 \& 2 (Department of Zoology, Kurukshetra University, Kurukshetra, Haryana, India -136119)
}

\begin{abstract}
The chromosomes obtained from scarab beetle Gymnopleurus mundus Wied., 1819 of subfamily Scarabaeinae were studied using standard staining and C-banding. The karyotype is comprised of 14 chromosomes with meioformula, $6 A A+X y p$. The analysis of constitutive heterochromatin $(\mathrm{CH})$ revealed small blocks located in the centromeric region of all chromosomes. Some of the anomalies like polypoidy, decondensation, stickyness and fragmentation of the chromatids were also encountered. The reduction of chromosome number and with conserved sex chromosome mechanism in G. mundus as compared to other Gymnopleurus spp. is suggestive of the Robertsonian fusion of autosomes having played some role in the evolution of karyotype in this genus.
\end{abstract}

Keywords: Scarabaeinae, Gymnopleurina, Gymnopleurus, Karyotype, Chromosomal analysis

\section{Introduction}

The Scarabaeinae constitute a highly diverse subfamily that comprises about 5,000 described species belonging to 234 genera spread widely in the world [1]. Most of the 85 Scarabaeinae species which are known cytogenetically have a chromosome number varying from $2 n=12$ to $2 n=20$, with the Xyp type being the most prevalent sex chromosome mechanism [2,3].

The genus Gymnopleurus Illiger, 1803 (Scaradaeinae: Scarabaeidae), whose distribution is Palearctic, Afrotropical and Oriental [4] comprises about 50 species [5], but only five of them have been partly investigated from karyological point of view. According to some of the reports haploid number $\mathrm{n}=10$ for $G$. koenigii [6], the diploid number $2 \mathrm{n}=18$ for G. sinatus [7], $2 \mathrm{n}=20$ for G. cyaneus [7], $2 \mathrm{n}=20$ for G. sturmi [3] and $2 \mathrm{n}=18$ for G. geoffroyi [8] has been established. Since information on these insects as meagre as compared to other genera of polyphagan beetles, the present communication deals with the chromosomal analysis of $G$. mundus by means of Geimsa staining and C-banding. This is a new cytological record of the subtribe Gymnopleurina, whose phylogeny is still controversial [9].

\section{Materials And Methods}

Sexually mature male specimens of Gymnopleurus mundus Wied., 1819 were collected from Seonti forest, Kurukshetra (Haryana, India) in months of August and September, 2009. All the specimens were identified following the guidelines laid down by taxonomist Arrow [11]. Chromosomal preparations were obtained, using the air drying method [12] from male gonads. C-bands were determined using the procedure described by researcher Sumner [13]. Evaluation of chromosomal morphology was based on ten spermatogonial metaphases. Percentage relative length of chromosomes was also calculated. Spermatogonial metaphase and other meiotic stages were analysed, photographed and karyotypes were prepared.

Gymnopleurus mundus Wied. 2n=14

\section{Results And Discussion}

Spermatogonial metaphase was characterised by the presence of 14 chromosomes (Fig.1). The karyotype comprised of six pairs of autosomes and sex chromosomes X and y (Fig. 2). The ideogram of the chromosomes represented the location of centromeres in chromosomes (Fig.11). Autosomal pairs 1 to 3 are metacentric, pairs 4 and 5 are submetacentric and remaining one pair 6 is acrocentric. The autosomes showed a gradual decrease in size. The $\mathrm{X}$ chromosome is subtelocentric whereas y is acrocentric. Percentage relative length of autosomes varied from 5.27 to 18.75 whereas that of $\mathrm{X}$ is 17.41 and $\mathrm{y}$ is 8.32 (Table 2). The analysis using C-banding technique allowed the identification of small constitutive heterochromatic blocks located in the centromeric region of all chromosomes (Fig. $3 \& 4$ ). During pachytene stage elongated thread like chromosomes appeared (Fig. 5). Stickiness and fragmentation of the chromatids was observed atpachytene stages (Fig.6). G. mundus also showed the polypoid nuclei at different stages of spermatogenesis like spematogonial prophase and spermatogonial metaphase (Fig. 7). Metaphase I revealed 6 autosomal bivalents in the form of highly condensed rods and the sex parachute (Fig. 8 \& 9). Due to chromatid separation the morphology of the chromosomes is very clear at metaphase II (Fig. 10). The haploid number at metaphase II and number of bivalents at metaphase I confirmed the diploid number counted at spermatogonial metaphase. 
Scarabaeinae (Coprinae) is less conservative subfamily of Scarabaeidae [14]. Unlike other scarabs there are much more variations in the form and size of chromosome numbers. But as in most of other scarabs the sex chromosome mechanism in Scarabaeinae is mainly Xyp type.

In the present chromosomal analysis of G. mundus is a new cytological record of Scarabaeinae. A perusal of literature on Gymnopleurus in TABLE 1, indicated the chromosome number, $2 \mathrm{n}=18$ for $G$. geoffroyii [9] and G. sinatus [7], whereas that of G. koenigii [6] , G. cyaneus [8] and G. sturmi [3] is 2n=20 which is the modal number of polyphagan beetles. But unlike all these species of Gymnopleurus cytogenetically analysed till date, the diploid number, $2 \mathrm{n}=14$ of $G$. mundus is lowest of all other species given in TABLE 1 . But the sex chromosomal mechanism was conserved in all the species of Xyp type.

Six pairs of autosomes as subtelocentric and acrocentric in G. sturmi with $2 \mathrm{n}=20$ [3], whereas, four pairs of autosomes as acrocentric in G. geoffroyi with $2 \mathrm{n}=18$ [9] have been reported. But in the present study, G. mundus with $2 \mathrm{n}=14$ possessed only one pair of autosomes as acrocentric. Acrocentry being the primitive evolutionary behaviour of the chromosomes, this decrease in the diploid number, number of acrocentrics and subtelocentrics from G. sturmi [3] to the G. mundus (present study), with conserved sex chromosomes is probably the resultant of pericentric inversions followed by fusions [15] as observed in other species belonging to Scarabaeidae, for instance, Bubas bubalus $2 n=18$, Xy [9], Dichotomius geminatus $2 n=18$, Xyp [15], Isocopris inhiata $2 n=18$, Xyp [16], and Macraspis festiva $2 n=18$, Xyp [17]. This occurrence of extensive karyotypic reorganisation leading to a more stable karyotype at least at autosomal level.

The centromeric C-banding pattern observed in G. mundus is quite common among Scarabaeidae representatives and also to Coleoptera as a whole $[17,18,19,20,21,22,23,24,25]$. Meanwhile, particular cases of $\mathrm{CH}$ distribution have been reported in some Scarabaeidae; Cetonia aurata and Bubas bison have $\mathrm{CH}$ blocks located in the terminal region of eight autosomal bivalents, in addition to the pericentromeric blocks [20, 26, 27]. In some species of Scarabaeidae, such as Diabroctis mimas and Isocopris inhiata, the occurrence of diphasic chromosomes that present one heterochromatic and another euchromatic arm has been described [16]. In addition to these patterns, there are still some species with almost total heterochromatic chromosomes or with $\mathrm{CH}$ absence. In Lygirus ebenus, Geniates borelli and Pelidnota pallidipennis, the $\mathrm{X}$ chromosome is almost totally heterochromatic, while the $\mathrm{Y}$ do not show $\mathrm{CH}$ blocks [17]. $\mathrm{CH}$ distribution was centromeric and pericentromeric in G. sturmi [3] and G. geoffroi [9]. CH bands also found in the metaphase I plate revealed the terminal localisation of heterochromatin. Using conventional staining, it has been proposed that the occurrence of autosome fusions is the main reason in reduction of chromosome number [15].

Polyploid nuclei in spermatogonial prophase and metaphase in $G$. mundus agree with some of the workers [28], who suggested that in all multicellular animals and plants certain tissues regularly consist wholly or in part of polypoid cells, whose nuclei contain multiples of the basic number of chromosomes. Sporadic occurrence of polyploidy nuclei in the germ cells of Coleoptera was observed by some of the researchers [ 29 , 30, 31, 32]. Such polyploidy may have possibly originated either due to endomitosis [33] or by neighbouring nuclei [30] or by the lose of cytokenesis which follows the karyokinesis. Presence of polyploidy and stickiness of the chromatid material represents the anomalies in natural populations. This may be the reason for the variation in the karyotype reorganisation in different species of Gymnopleurus.

\section{Conclusion}

The autosomal fusion events are probably the main rearrangement responsible for the chromosome differentiation in this species, acting in diploid number reduction. The present study provides a new cytological record of the genus Gymnopleurus which joined to future cytological data on other species of the same genus will provide a set of potentially informative characters suitable to understand the phylogeny of subtribe Gymnopleurina which according to recent literature $[3,9,16,17]$ is still unclear. So, this new data helps to draw the phylogeny of the genus Gymnolpeurus .

\section{Acknowledgements}

Our thanks are due to Kurukshetra University Authorities for providing laboratory facilities and to Dr. Nidhi Kakker, Department of Zoology, Kurukshetra University, and Kurukshetra for her help in identification of beetles.

\section{References}

[1] I. Hanski, Y. Cambefort, Dung beetle ecology, (Princeton Univ. Press, Princeton, 1991).

[2] O. R. Vidal, Coleoptera from Argentina, Genetica, 65, 1984, 235-239.

[3] M.S. Colomba, R. Vitturi, M. Zunino, Karyotype analysis, banding and fluorescent in situ hybridisation in the scarab beetle Gymnopleurus sturme McLeay (Coleoptera Scarabaeoidea: Scarabaeidae), Journal of Heredity, 91 (3), $2000,260-264$.

[4] G. Halffter, W.D. Edmonds, The nesting behaviour of dung beetles (Scarabaeini). An ecological and evolutive approach . (Inst Ecologia, Mexico. 1972). 
[5] V. Balthasar, Monographie der Scarabaeidae and Aphodiidae der palearktischen und orientalishen region ( Tschec Akad Wissen., 1963).

[6] J. Dasgupta, The cytology of Cybister limbatus, Gymnopleurus Koenigii, Aulacophora intermedia and Alcides sp. (Insecta: Coleoptera), Proc. Zool. Soc. Calcutta, 16, 1963, 123-134.

[7] G.K. Manna, M. Lahiri, Chromosome complement and meiosis in forty-six species of Coleoptera, Chromosome Information Service, 13, 1972, 9-11.

[8] R.K. Kacker, Studies on chromosomes of Indian Coleoptera IV. Chromosome number and sex determining mechanism in nine species of family Scarabaeidae, Nucleus, 13, 1976, 126-131.

[9] R. B. Angus, C. J. Wilson, D. J. Mann, A chromosomal analysis of 15 species of Gymnopleurini, Scarabaeini and Coprini (Coleoptera : Scarabaeidae), Tijdschr. Entomol., 150, 2007, 201-211.

[10] Y. Cambefort, Biogeography and Evolution, in Hanski I and Cambefort Y, (Ed.), Dung beetle ecology. (Princeton, NJ: Princeton University Press 1991) 51-67.

[11] G. J. Arrow, The fauna of British India Including Ceylon and Burma, (Col. Lamella. III (Coprinae) (Taylor and Francis, London, 428 p., 1931).

[12] J. S. Yadav, E. A. Lyapunova, A simple and rapid method for making karyological preparations from Coleoptera Insects, Nucleus, $26,1983,159-162$.

[13] A. T. Sumner, A simple technique for demonstrating centromeric heterochramatin, Exp. Cell Res., 75, 1972, $304-306$.

[14] J. S. Yadav, R. K. Pillai, Karyological investigations on seven species of Coprinae (Scarabaeidae: Coleoptera), Caryologia, 30, $1977,255-263$

[15] D. C. Cabral-De-Mello, F. A. B. Silva, R. C. Moura, Karyotype characterization of Eurysternus caribaeus: the smallest diploid number among Scarabaeidae (Coleoptera: Scarabaeoidea). Micron, 38, 2007, 323-325.

[16] E. G . Bione, M. L. Camparoto, Z. L. P. Simoes, A study of the constitutive heterochomatin and nucleolus organizer regionsof Isocopris inhiata and Diabroctis mimas (Coleoptera:Scarabaeidae, Scarabaeinae) using C-banding, AgNO3 stainingand FISH techniques, Genet. Mol. Biol., 28 , 2005a, 111-116.

[17] E. G. Bione, R. C. Moura, R. Carvalho, M. J. Souza, Karyotype, C-and fluorescence banding pattern, NOR location and FISH study of five Scarabaeidae (Coleoptera) species, Genet. Mol. Biol. 28, 2005b, 376-381.

[18] R. C. Moura, M. J. Souza, N. F. Melo, A. C. Lira-neto, Karyotypic characterization of representatives from Melolonthinae (Coleoptera: Scarabaeidae): Karyotypic analysis, banding and fluorescent in situ hybridization (FISH), Hereditas, 138, 2003, 200206.

[19] M. S. Colomba, R. Vitturi, N. Volpe, A. Lannino, M. Zunino, Karyotype, banding and rDNA FISH in the scarab beetle Anoplotrupes stercorosus (Coleoptera: Scarabaeoidea: Geotrupidae), Description and comparative analysis. Micron 35, 2004, 717720.

[20] M. S. Colomba, R . Vitturi, A. Libertini, A. Gregorini, M . Zunino, Heterochromatin of the scarab beetle, Bubas bison (Coleoptera: Scarabaeidae) II. Evidence for AT-rich compartmentalization and a high amount of rDNA copies. Micron, 37, $2006,47-51$.

[21] M. Rozek, D. Lachowska, E. Petitpierre, M. Holecov'A, C bands on chromosomes of 32 beetles species (Coleoptera: Elateridae, Cantharidae, Oedemeridae, Cerambycidae, Anthicidae, Chrysomelidae, Attelabidae and Curculionidae), Hereditas, 140, 2004, $161-170$.

[22] C. J. Wilson, R. B. Angus, A chromosomal analysis of ten European species of Aphodius Illiger, subgenera Acrossus Mulsant, Nimbus Muldant and Rey and Chilothorax Motschulsky (Coleoptera: Aphodiidae), Koleopterol. Rundsch., 74, $2004,367-374$.

[23] C. J. Wilson, R. B. Angus, A chromosomal analysis of 21 species of Oniticellini and Onthophagini (Coleoptera: Scarabaeidae), Tijdschr. Entomol., 148, 2005, 63-76.

[24] C. J. Wilson, R. B. Angus, A chromosomal analysis of eight species of Aphodius Illiger subgenera Agiolinus Schmidt, Agrilinus Mulsant and Rey and Planolinus Mulsant and Rey (Coleoptera: Aphodiidae), Proc. Russ. Entomol. Soc., 77, 2006, $28-33$.

[25] M. C. Schneider, M. C. Almeida, S. P. Rosa, C. Costa, D. M. Cella, Evolutionary chromosomal differentiation among four species of Conoderus Eschscholtz, 1829 (Coleoptera, Elateridae, Agrypninae, Conoderini) detected by standard staining, C-banding, silver nitrate impregnation, and CMA3/DA/DAPI staining, Genetica, 128, 2006, 333-346.

[26] M. S. Colomba, E. Monteresino, R. Vitturi, Z. Zunino, Characterization of mitotic chromosomes of the scarab beetles Glyphoderus sterquilinus (Westwood) and Bubas bison (L.) (Coleoptera: Scarabaeidae) using conventional and banding techniques, Biol. Zent. Bl., 115, 1996, 58-70.

[27] A. M. Dutrillaux, S. Moulin, B. Dutrillaux, Use of meiotic pachytene stage of spermatocytes for karyotypic studies in insects, Chrom. Res., 14, 2006, 549-557.

[28] M. J. D. White, Animal cytology and evolution (3 ${ }^{\text {rd }}$ ed.) (Cambridge: Cambridge University Press, 1973)

[29] W. M. Goldsmith, A comparative study of the chromosomes of the tiger beetles (Cicindelidae), J. Morphol. 32, 1919, 437-487.

[30] S. G. Smith, N. Virkki, Animal cytogenetics (3) (Berlin,West : printed in West Germany1978).

[31] J. S. Yadav, Karamjeet, Chromosome study on three species of Cicindellidae (Adephaga: Coleoptera) from Haryana, Zool. Anz. Jena., 206, 1981, 121-128.

[32] J. S. Yadav, M. R. Burra, Karyological investigations on cylinder Westwood (Coleoptera: Cicindelidae). Elytron Suppl., 5(1), 1991, 177-188.

[33] G. P. Sharma, O. P. Mittal, J. S. Yadav, Chromosome behaviour in an Indian grasshopper Tryxalis indica, Thumb. Res. Bull. (N.S.) Panjab Univ., 25, 1974, 1-4. 


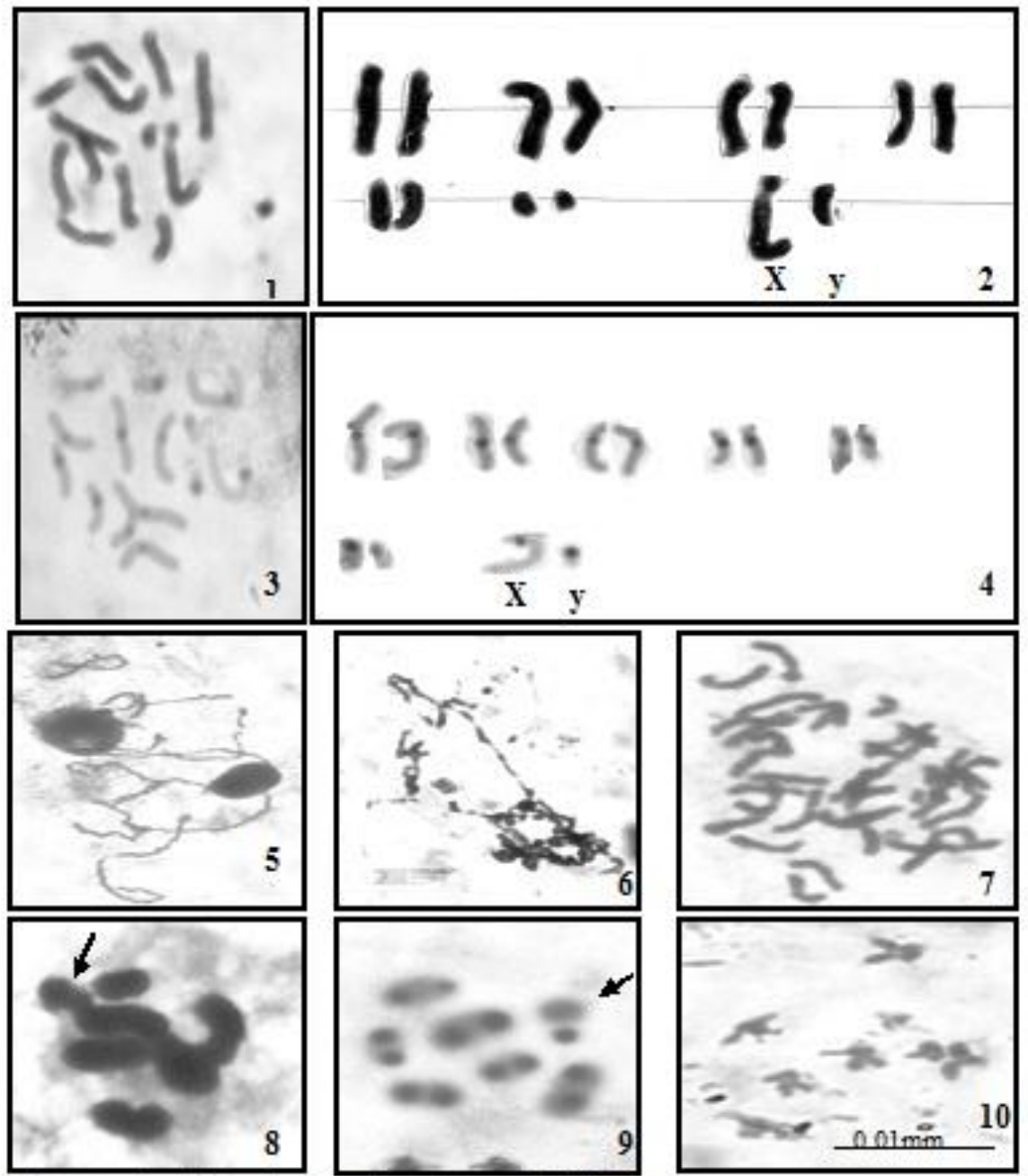

Figures (1 - 10) Gymnople urus mundus Wied.

1. Spermatogonial metaphase; 2 . Karyotype; 3. C- banded Spermatogonial metaphase; 4 . C- banded Karyotype ; 5. Pachytene; 6. Stickyness in Pachytene; 7. Polyploidy in

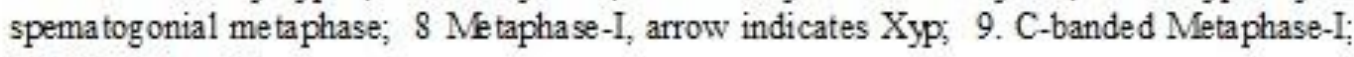
10. Metaphase-II

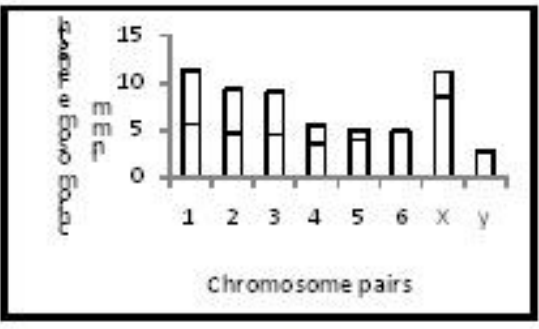

Fig. 11 . Diagrametic representation of average karyotype of $G$. mundus 
A new diploid chromosome number in Gymnopleurus Illiger, 1803 (Coleoptera: Scarabaeidae,

Table 1. Chromosomal analysis of Gymnopleurus spp.

\begin{tabular}{|l|l|l|l|l|}
\hline Sr.No. & Species & $\begin{array}{l}\text { Diploid } \\
\text { number } \\
(\mathbf{2 n})\end{array}$ & Meioformula & Reference \\
\hline 1 & G. koenigii & 20 & $9 \mathrm{AA}+\mathrm{Xyp}$ & Dasgupta, 1963 \\
\hline 2 & G. cyaneus & 20 & 9AA+Xyp & Kacker, 1976 \\
\hline 3 & G. sturmi & 20 & $9 \mathrm{AA}+\mathrm{Xyp}$ & Colomba et al., 2000 \\
\hline 4 & G. sinatus & 18 & $8 \mathrm{AA}+\mathrm{Xyp}$ & Manna \& Lahiri,1972 \\
\hline 5 & G. geoffroyi & 18 & 8AA+Xyp & Angus et al. 2007 \\
\hline 6 & G. parvus & 18 & $8 \mathrm{AA}+\mathrm{Xyp}$ & Unpublished \\
\hline 7 & G. miliaris & 36 & 17AA+Xyp & Unpublished \\
\hline 8 & G. mundus & 14 & 6AA+Xyp & Present report \\
\hline
\end{tabular}

Table 2. Percentage relative length of chromosomes of Gymnopleurus mundus

\begin{tabular}{|l|l|}
\hline Chromosomal pairs & $\begin{array}{l}\text { percentage relative length of } \\
\text { chromosomes }\end{array}$ \\
\hline Pair no. & 18.75 \\
\hline 1 & 14.3 \\
\hline 2 & 13.1 \\
\hline 3 & 12.5 \\
\hline 4 & 10.2 \\
\hline 5 & 5.27 \\
\hline 6 & 17.41 \\
\hline $\mathrm{X}$ & 8.32 \\
\hline $\mathrm{y}$ & \\
\hline
\end{tabular}

